\title{
Leprosy in the Leeward and Windward Islands.
}

R. G. Cochrane

7 HE Leeward Islands consist of Dominica, Antigua, Montserrat, St. Kitts and Nevis. The seat of govern1 ment is at Antigua and each island is administered by an Administrator. It is interesting to note that in those islands where the economic conditions are fairly satisfactory, there appears to be little leprosy of endemic importance.

\section{Dominica}

This island is 29 miles long and 16 miles broad, and has a population of 44,000. Dominica is the most mountainous island of the group, the interior of which is almost inaccessible by ordinary means. The chief towns are along the coast, and the easiest approach to these is by means of motor launch. Of the islands of this group Dominica and St. Kitts have the highest incidence of leprosy. The disease occurs in two chief centres, one around Roseau and the other in the southernmost town of Souffriere. There has been considerable concern regarding the spread of 
leprosy within recent years, and there is justification for such anxiety. In the first place there is no segregation of the open case, and there is evidence that children are being infected; this is especially so in the Souffriere area. The total number of cases reported in the island is some 37, but no detailed survey or examination of contacts has been made, and therefore the number may be considerably higher. It is evident, however, that leprosy is an important endemic disease, and more active measures should be taken for its control. These might include :-

(1) Establishment of a settlement for the open case.

(2) Examination and follow up of contacts and school children in areas where the disease is known to be prevalent.

(3) Observation and/or treatment of early non-infective cases.

(4) Propaganda in schools and education of responsible authorities in the prophylaxis and control of leprosy.

Dominica presents a unique opportunity for starting from zero and demonstrating the possibility that leprosy is a disease possible of control. It is hoped that an antileprosy scheme will be organised which will deal with leprosy as a public health problem, and not be an attempt only to segregate and treat all known cases of the disease in the island without relation to the type of the disease or to areas and spread in the country. Special emphasis should be laid on the incidence among children and the preventing of children and adolescents from coming into contact with open cases.

\section{Antigua}

Antigua, the seat of the government of the Leeward Islands, has an area of 108 square miles, and a population of approximately 52,000 (1932). The incidence of leprosy as judged by the number of inmates in the Home, does not appear high. This is certainly the case if the position is compared with that of St. Kitts, with approximately half the population and the number of known cases between 60 and 70. There are 18 cases isolated in the Home, four of whom come from other islands. Cases seem to be sent in from all the parishes of the island, but as is to be expected, the greater number come from the more populated parishes of St. John's and St. George's, in which the two chief towns are situated. The low incidence of leprosy in the island is probably due to the better economic condition. Although leprosy does not appear to be prevalent in the island it has 
been suggested that further enquiries might be instituted, in order to ascertain whether there are definite foci from which they are arising, e.g., it might be profitable to examine school children and contacts of existing cases. It is interesting to note that the great majority of cases in the institution are of an extremely severe kind, suggesting that even though the disease may be tending to diminish, it does not necessarily mean that the type of case is less severe.

All the inmates are African in origin, and it appears that the racial factor may not be unimportant in determining the type of disease.

\section{MonserRat and Nevis}

It is unnecessary to dwell on the position in these islands as the sporadic cases which arise are transferred to a settlement on one of the other islands.

\section{ST. Kitts}

St. Kitts is one of the smaller islands of the Leeward group. It has a population of 18,000 (1932), and is 28 miles long and 5 miles broad. Economically the inhabitants appear to live on a very low level. The staple product is sugar, and the soil seems to be of such a poor nature that very little else will grow. This means that if the sugar market is depressed the island suffers economically. The straightened economic condition of the island strikes a visitor forcibly, especially if he should be coming from islands such as Grenada and Antigua. Owing to these facts it is not surprising to find that the incidence of leprosy appears to be fairly high. There is an institution in St. Kitts about 6 miles out of the capital town of Basseterre, in which there were isolated at the time of my visit, 53 cases. In addition to those isolated in the leprosy hospital there were some 27 known cases in the island who were also cared for by the doctor in charge of the Home, who visits them periodically, giving them treatment. These cases came chiefly from Basseterre, but others were scattered over the island. Of the 53 cases in the institution, 3 were 20 years and under, and there were 35 males and 18 females. The majority of the cases were of the very advanced cutaneous type.

The total number of known cases in the island therefore at the time of my visit was 70. Ten of the cases in the Home came from one or other of the smaller islands. The Home is well organised and recreational facilities are provided for the inmates. The seriousness of the situation so far as leprosy is concerned is revealed on closer examination. Although one was only able to examine in a very cursory 
manner the contacts in the capital town of Basseterre, it was somewhat of a surprise to find that in every case of nodular leprosy whose contacts were examined, one to three children had become infected. This means therefore, that to obtain a probable estimate of the number of cases in the island, it would be legitimate to double the figure of known cases. This would give an incidence of 140 out of a population of 18,000 , or 0.8 per cent. In view of the fact that the number of children infected seems to be fairly high, it is legitimate to conclude that leprosy is probably spreading in St. Kitts. The houses in which the disease occurs in Basseterre are of a very poor type. They are crowded together cheek by jowl with innumerable children in and around the vicinity. Such are the conditions that all the elements required for the spread of the disease are present, and the fact that open cases in the advanced cutaneous stage are at large in an area where children are under grave risk of infection, and where the economic conditions are very poor, makes the probability almost a certainty that the disease will spread further. The authorities are alive to the position in St. Kitts, and measures have been suggested for the control of the disease The following points have been emphasised :-(1) Examination of all school children in the island; (2) Isolation of all open cases in the settlement; (3) Observation of all contacts of cases discovered; (4) Treatment and/or observation of early neural cases discovered, especially among children; (5) Propaganda among the public and medical profession concerning treatment, the mode of spread of the disease and methods of control. Leprosy should not be impossible of control in a small island such as this, and it will be interesting to watch the situation develop, for valuable lessons could be learned from a concerted attempt to control the disease in the island.

\section{WINDWARD ISLANDS}

The Windward Islands consist of St. Vincent, St. Lucia and Grenada, and the seat of the Government is at Grenada. ST. VINCENT

St. Vincent is 11 miles in length and 12 miles in breadth and has a population of 47,961 (1932).

The total number of cases segregated in the island is 17 , all of whom are adults. Accurate information as to the foci of the disease is not available, and therefore, it would be difficult to say whether there is any evidence that the disease is of any real endemic importance. Conditions 
under which sufferers are segregated are not altogether satisfactory, and suggestions have been made concerning this. As far as present evidence goes there does not seem to be any real need for further active steps to be taken, as there seems little indication that leprosy is an important public health problem.

\section{St. LUCIA}

This island is 27 miles in length with a breadth of 14 miles, the population being 59,676 (1932). There is a settlement for those suffering from leprosy at Rat Island, which is an island off the coast some 60 miles from the capital town. I was unfortunately too short a time on shore to enable me to visit this settlement. There seems to be some indication that there is a small focus of leprosy some 9 miles from Port Castries. This is a fishing village where from time to time cases have arisen. A superficial and hasty examination of one of the schools was made, and 200 scholars were examined, no cases being discovered. There seems, however, to be some justification for a complete examination of all school children in the village. It appears that there may be a problem needing attention, but until further data are amassed it is impossible to say whether leprosy is an important disease or not. Recommendations have been made regarding lines along which enquiries might be made.

\section{GRENADA}

The area of Grenada is 21 miles in length and 12 miles in breadth, and the population is 66,302 (1932). Of all the islands in the group this appears to be economically in the most satisfactory condition, and it is interesting to note that leprosy does not appear to be a problem of any magnitude. The Home, some 7 miles from the capital, St. George's, is adequate for the purpose, and is neat, tidy and well cared for. The number in the Home is 13, and the last case reported some 18 months ago was an expatriated case from Trinidad. The last indigenous case was discovered some 3 years ago, and there has been no instance of childhood infection for many years.

The general situation indicates that apparently conditions in the island are such that the disease tends not to spread, and there is no evidence that further steps need to be taken with regard to the control of the disease.

It is suggested by some authorities that there should be a central home for the smaller islands of the Leeward and Windward group. It is admittedly expensive to organise a leprosy settlement only for a few cases, such as 
exist in Grenada, St. Vincent and Antigua, but on the other hand the islands are so far separated that there would be considerable objection to transporting lepers a distance from their homes. If this were done it would be very difficult for the authorities to discover cases, because it would cause individuals to hide themselves. From many points of view one central settlement has attractions, but the problem of transportation, and of the undesirability of taking individuals far away from their homes, give rise to difficulties which would be hard to overcome. 